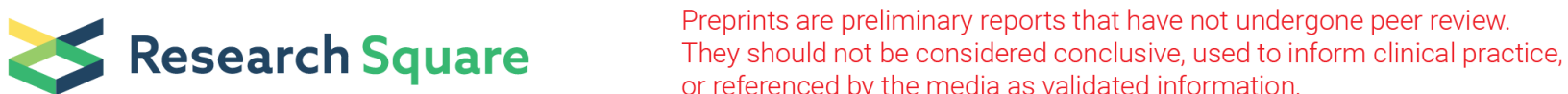

\section{Identifying Public Stakeholders Effective on Mental Health Promotion in Iran}

\section{Behzad Damari}

Tehran University of Medical Sciences

Mohammad Reza Amir Esmaili

Kerman University of Medical Sciences

noora rafiee ( noorarafiee@ymail.com )

kerman university of medical sciences,iran https://orcid.org/0000-0002-3947-2326

Ahmad Hajebi

Iran University of Medical Sciences

\section{Research article}

Keywords: Stakeholder participation, Health promotion, Mental health

Posted Date: August 12th, 2020

DOl: https://doi.org/10.21203/rs.3.rs-37155/v1

License: @ (i) This work is licensed under a Creative Commons Attribution 4.0 International License. Read Full License 


\section{Abstract}

Background: It is not always easy to put mental health on the agenda of sectors other than the health sector. However, it is now confirmed that mental health promotion policies need innovations beyond the scope of the health sector to be efficient. Thus, in this study, an attempt was made to identify the most effective stakeholders of the public sector in the field of mental health promotion in Iran to help the policy-makers of said sector and to encourage the intersectoral cooperation and further involvement of these effective sectors in mental health promotion plans.

Methods: This was a mixed-methods study. From the data of the first step (literature review and a survey involving professors of relevant disciplines), the names of government agencies related to the domain of mental health were extracted. In the second step, a checklist was developed, the horizontal axis of which was the relevant organizations and the vertical axis was the social risk factors effective on mental health promotion. The data of this step were analyzed by the simple additive weighting method. In the final step, a table was plotted in the form of institutional mapping in order to summarize the organizations affecting each risk factor.

Results: The Islamic Consultative Assembly, the Ministry of Interior, the Islamic Republic of Iran Broadcasting, the Ministry of Cooperatives, Labor, and Social Welfare, and the Ministry of Education were identified as five organizations with the greatest impacts on the social determinants of mental health promotion in Iran.

Conclusions: Significant impacts can be exerted by institutions such as the Islamic Consultative Assembly (as the legislator), the Ministry of Interior and its subsidiary entities such as municipalities and governors (as the administrators of homeland security and support for safe and appropriate urban and local facilities), the Islamic Republic of Iran Broadcasting (as the national media), the Ministry of Cooperatives, Labor, and Social Welfare (as the institution in charge of employment, job security, and social welfare), and the Ministry of Education (as the educational institution of the country).

\section{Background}

Investment in mental health promotion is essential because, following the increased prevalence of mental disorders, various social, security, and legal harms have also expanded; based on the statistics, these harms reduce the productive power of the society (1). The high rates of common mental disorders and suicide are attributed to poverty, poor education, material losses, social isolation, deprivation, and unemployment (2-4). In Iran, the prevalence of mental disorders varies from $6.11 \%$ in Yazd Province to $39.1 \%$ in Chaharmahal and Bakhtiari Province (1).

Some social problems are considered simple due to being associated with a specific domain with certain players who have accepted their ownership and responsibility in that field, whereas some others are viewed as complex, in some problems often encountered in the domain of health such as obesity, the stakeholders try to evade their ownership in that field. In such cases, if these problems are even slightly associated with welfare and health, they are regarded as the responsibilities of the health sector by default $(5,6)$.

Mental health is a complex social problem and many administrators play a role in its promotion. The focus of governments on maintaining and promoting mental health is a means to having a healthier, safer, more educated, and productive society that leads to the cooperation of various governmental and nongovernmental sectors on mental health determinants. Mental health promotion has traditionally been recognized as the responsibility of the health sector. However, upon looking at its effective determinants, it is found that the health sector has a small share in the determinants of mental health, and other institutions and organizations such as the industry, commerce, housing, sports, welfare, and education can exert positive and negative effects on these determinants, although they are often unaware of their impacts. Therefore, the participation of these sectors in mental health promotion should be encouraged (7).

Mental health promotion strategies are often focused on environmental and psychosocial determinants, such as living conditions, education, income, employment, access to community resources, social support, and individual competencies. Over the last 25 years, many studies have been conducted on mental health promotion in different countries and offered recommendations in this field. The inter-sectoral health actions with other organizations include health promotion schools and career-promoting courses in the Zhejiang province, China, for mental health promotion, which will have an outcome for the health sector and other cooperating sectors (8).

The lack of a balanced approach in mental health policy to determine an equal weight for promotion, prevention, treatment, and rehabilitation has reduced the awareness of health policy-makers about the positive mental health. Moreover, in the field of health promotion, the physical aspect of health promotion has received higher attention than its psychological aspect, and there is also confusion about the meaning of the term mental health among both healthcare professionals and policy-makers. As such, the term is often used to refer to mental illness, treatment, and related services (8).

In the present era, health can be interpreted as an innovative expression of inter-sectoral actions that emphasize a comprehensive perspective of health, social welfare, social justice, economic development, and environmental protection $(9,10)$. Although the definition of health in all policies involves all sectors, it does not ensure that all sectors be involved in all innovative actions; rather, it ensures that the organization is aware of the impact of its performance on health and takes responsibility for this matter (10). Now, a question is raised: Who is responsible for mental health promotion in society? Who are the stakeholders in this field?

Stakeholders are the players who have interests in a particular field and would like to maintain those interests. Based on material resources, their position, and knowledge, they have special opportunities to affect events and play an important role in planning and implementing interventions. The term stakeholders refers to all public and private groups in society that are linked to one another based on common needs and values, and as an organized group they express their interests in various ways, including negotiation, discussion, alliances with other stakeholders, advocating for laws of democracy or coercion (11). 
Identifying stakeholders before starting a policy or program reduces the potential misunderstandings or oppositions to the policy or program and positively affects its successful implementation (12). Given that stakeholder identification is a dynamic process and the economic, social, political, and cultural conditions of societies are constantly evolving, this study sought to identify the most influential stakeholders in the field of mental health promotion with respect to recent developments in the demographic, economic, and political conditions of Iran.

\section{Methods}

This was a mixed-methods (qualitative-quantitative) study. The data of the first step were extracted through a literature review and a survey with two professors of health management and inter-sectoral collaboration to extract the names of governmental organizations and institutions in the field of mental health. Seventeen governmental organizations influential on mental health promotion were identified. In the next step, based on the World Health Organization (WHO) reports of 2002 (13), 2004 (14), 2008 (15), and 2012 (16), and upon seeking the opinions of two members of the research team and adding some items, 32 social risk factors affecting mental health promotion were identified. A checklist with the horizontal axis of relevant organizations and the vertical axis of social determinants affecting mental health promotion was developed. The checklist was completed by two groups. For the first group, opportunistic sampling was performed. Executive experts from different fields of health from different province of Iran who attended the master of public health (MPH) courses at the Ministry of Health and Medical Education were recruited. They were chosen because they had knowledge of different fields of health, at least five years of experience in various areas of health promotion, and a master's degree or above. Due to their involvement in inter-sectoral collaboration in the field of health, orientation of participants on the fundamentals of intersectoral collaboration for 2 hour held. After obtaining verbal consent for participation, they were asked to answer questions during the next hour with regard to what they have learned from the inter-sectoral collaboration and experiences in different domains of health. They were 10 person and all of them filled out the relevant checklist (response rate: 100\%). In order to further enrich the study, the perspectives of other relevant fields in the area of the social determinants effective on health were sought via purposive sampling. Since the second group consisted of seven academic experts who were already familiar with the subject under study, we were assured that two groups were familiar with what we meant intersectoral collaboration. In the second group, seven individuals with over five years of academic experience in the field of health were asked to complete the checklist that was sent to them by email, and eventually four people sent back their responses (response rate: $57.14 \%$ ).

The scores ranged from 1 (irrelevant) to 3 (relevant). The organizations and ministries with the highest scores were identified as the most effective stakeholders in this field; thus, simple additive weighting (SAW) was performed. This technique is one of the simplest multi-criteria decision-making methods (17) and .This method is conducted as follows:

Step1: Quantifying the decision matrix

Due to the quantitative nature of the data in this study, there was no need to perform this step for this study. Step2: Linear non-scaling of the decision matrix value

This is performed for the quantified decision matrix, and the result is a non-scaled matrix as shown in Additional File 1 by this formula:

$$
P_{i}=\sum_{j=1}^{k} w_{j} \cdot r_{i j} \quad ; \quad i=1,2, \ldots, m
$$

Step 3: Multiplying the non-scaled matrix by the scale of criteria

In this step, the non-scaled matrix is multiplied by the weights of the criteria. The result is a columnar matrix.

$r_{U}=\frac{d_{J}^{M m n}}{d_{U}}: \quad d_{J}^{M m n}=\operatorname{Min}_{1 \leq t \leq m} d_{U}: j=1.2 \ldots k$

In these formulas.

rij: the normalized values of decision matrix elements

Minij: the minimum value of each row and column ( Maxij for positive attributes, Minij for negative attributes affecting mental health, e.g. mental health risk factors)

dij: a special value of the jth attribute for the ith alternative

Wj: the specified weight. In this study, for 32 risk factors, the same weight of 0.02 was considered based on the opinion of the research team.

In the final step, a table was tabulated in the form of mapping to summarize the organizations affecting each determinant (Table 3 ) to further clarify the role of each organization. The mapping was performed such that the organizations with three highest scores on each social risk factor affecting mental health promotion were identified and labeled as the most effective institutions on that factor. In cases where two institutions received the same score for a certain risk factor, both institutions were labeled as having the greatest impact. 


\section{Results}

In the present study, $78 \%$ of the participants were women and most of them belonged to the age group of $45-50$ years. Moreover, $72 \%$ of the participants had a master's degree in various health-related disciplines, $14 \%$ were social medicine specialists, and $14 \%$ had a PhD in psychology (Table 1 ).

The data from the SAW analysis showed that from among 17 known organizations with considerable impacts on mental health promotion, the Islamic Consultative Assembly, the Ministry of Interior, the Islamic Republic of Iran Broadcasting, the Ministry of Cooperatives, Labor, and Social Welfare, and the Ministry of Education were identified as five organizations with the greatest impacts on the social determinants affecting mental health promotion (Table 2).

A more precise evaluation of the data revealed that in each risk factor related to mental health promotion, several institutions or organizations play a more prominent role; thus, based on the frequency of the highest scores for each dimension, and to simplify the results, the following table is presented (Table 3 ). The logic of this table is based on the first three ranks that the respondents believed that each organization has the greatest impact on risk factors; In cases where the score of some risk factors was similar to each other, instead of three factors, 4 or 5 factors were marked for the desired organization in the table.

\section{Discussion}

This study aimed to identify organizations that are the most effective on mental health promotion. The results indicated that five institutions, namely the Islamic Consultative Assembly, the Ministry of Interior, the Islamic Republic of Iran Broadcasting, the Ministry of Cooperatives, Labor, and Social Welfare, and the Ministry of Education rank the highest. The results confirmed the impact of all three executive, legislative, and judicial branches on the determinants of mental health. Of these, the executive branch (including various ministries and broadcasting organizations) and the legislative branch exerted a significant impact because the five primary effective institutions belonged to these two branches.

Optimal interactions in the relations between governmental institutions are regarded as a key component in the management of the country. One such area of interaction is the mutual cooperation of the legislative branch and the executive branch based on the law and the application of managerial techniques (18). The legislative branch of the government is responsible for creating common norms through the approval and regulation of laws and bringing people together as one nation. The judicial branch of the government is responsible for protecting the value system and cohesion, and addressing the disputes between individuals and the government or public organizations based on laws and regulations. In addition, the executive branch consists of the president, the prime minister, the cabinet of ministers, ministries, government employees, the administrative system, and military and law enforcement (19). Due to the plurality of determinants and entities, the following explanations are presented about the five institutions with the greatest impacts on some determinants of mental health promotion.

\section{Role of the Islamic Consultative Assembly in mental health promotion}

The Islamic Consultative Assembly is the legislative authority in Iran and can enact laws on general issues within the limits prescribed by the Constitution; however, the laws must not conflict with the principles of the official religion or the constitution; "Parliament in Iran cannot delegate its legislative powers to other persons or entities" (20). Prioritizing mental health promotion in the parliament and taking into account the impacts of laws in the process of approval on society's mental health have made the role of the parliament vital in this field.

Lack of attention to human rights (freedom of expression, fair trial, freedom of thought and religion, etc.), lack of trust in the government in reflecting the facts, and lack of involvement of people in relevant decisions are the factors that negatively affect the mental health of people by creating an atmosphere of distrust, indifference, and loss of social capital in society. The importance of attention to human rights and updating them in the society in accordance with the domains involved in mental health (Prison Organization, Judiciary, Ministry of Health, Police, etc.) and passing specific laws (21) have been considered significant in dealing with cases that may affect the society's mental health. For example, studies indicate that one-third of inmates are homeless upon arrival, and another one-third lose their homes as a result of imprisonment (22); therefore, investigating the conditions of prisoners and their return to home and employment can play a key role in mental health promotion. The way that the government deals with crimes in the country affects the mental health of people. In this regard, the parliament should provide safer policies to identify and care for prisoners because they are at risk of suicide and self-harm. The criminal justice administrations should be aware that not only the detainees, but also other people involved with the justice system are at a higher risk of suicide and mental disorders (23). In this regard, education and culture promotion in broadcasting organizations, schools, and the Ministry of Culture will affect the acceptance of specific social groups and how people interact with them and their families.

The housing problem is one of the other risk factors impacting the mental health of society. The housing problem, financial insecurity, debt, and tenancy increase the risk of mental disorders, alcohol abuse, and drug abuse by three folds (24). Research has shown that homeless children are at risk of mental disorders three to four times more than other children (25). Meanwhile, the Islamic Consultative Assembly can play a major role by adopting plans and bills for preventing unreasonable housing price rise, supporting the tenants, and providing facilities to households without a house, through which it can reduce the mental burden caused by the inability to purchase or rent houses and thus improve the society's mental health. In this regard, the role of the Ministry of Economic Affairs and Finance and the Ministry of Roads \& Urban Development should not be ignored.

Social vitality is one of the other effective risk factors. The overall state of vitality in the Iranian society is not optimal (below average). Veenhoven believes that, at the macro level, vitality is dependent on the quality of society and factors such as health, justice, and freedom. According to him, the social status of people affects their happiness. Giddens also sees trust as a factor affecting happiness and believes that violent threats resulting from industrialization, war, lack of trust, and a sense of insecurity threaten happiness. Thus, mass celebrations will bring about happiness, lower tension, and lead to social action (26). 
Policymakers and legislators should thus consider this matter when planning to promote social vitality, which is one of the factors affecting people's health promotion, and approve and pursue useful plans and bills for this purpose.

\section{Role of the executive branch in mental health promotion}

The executive branch in Iran is composed of various ministries, and the Islamic Republic of Iran Broadcasting is one of its organizations.

\section{Ministry of Interior}

One of the tasks of the Ministry of Interior is to coordinate urban and rural construction development and provide guidance and technical support for municipalities. The Department of Social Affairs and Protection of Civil Rights is responsible for investigating the social phenomena and harms in society in collaboration with relevant organizations. It is also in charge of examining the policies, strategies, and efforts made to provide social justice and civil rights, and suggesting a plan to help decision-making authorities in promoting the aforementioned matters. The Ministry of Interior is also responsible for participation and cooperation with executive bodies to investigate the programs related to the mental and social health of society, public health, food security, social vitality, and improving life skills (27). In this regard, the Ministry of Interior can affect the provision of recreational facilities, which is an effective social determinant on mental health. Planning to create suitable sites, such as community centers, Internet cafes, green spaces, and safe playgrounds for children leads to social vitality in society and affects the mental health of people; however, these spaces are not properly distributed in deprived areas (28). Thus, the role of the mayors and governors in securing the civil rights of people becomes more prominent.

The role of the Ministry of Interior and the governorates in the field of mental health promotion is related to homeland security and the efforts to realize the social and political freedoms of individuals in society. Various studies have been conducted on this topic, reporting that the physical security (housing, house and neighborhood security), congestion, abandoned buildings, crime and sabotage, poorly constructed roads, traffic, humidity, lack of recreational facilities and green space, and noise are all causes of distress and depression. A systematic review showed that housing improvement interventions have a positive impact on physical and mental health (29), all of which can be promoted with the participation of municipalities, governors, and other provincial and municipal institutions.

Investigating the ways to implement public policies for promoting national unity and Islamic solidarity are other duties assigned to the Ministry of Interior (27). An important factor affecting society's mental health is the occurrence of war, unrest, and conflicts. Unrest and war disrupt the development of social and economic structures and well-being and cause long-term stress and psychological harms to children and adults (30).

\section{Islamic Republic of Iran Broadcasting}

Public radio and television networks serve the public interest; thus, one of their roles is to teach citizenship skills, civil behaviors, and social participation. One of the governing principles of broadcasting organizations is independence. This principle indicates that broadcasting should provide an appropriate arena for the free expression of opinions, and people should be able to easily access information. Hence, radio and television networks should not be dominated by a political party or even advertisers, so that the news and information can be impartial and transparent. Since the media are known as the interface between the government and people, they must be capable of broadcasting truthful news and information to society.

Broadcasting negative and fake news via the media causes tension and stress in people, and thus negatively impacts the mental health of people because it always induces a sense of confusion, despair, and distrust in the government and the news. The responsibility of broadcasting news via the national media is another factor that affects mental health; for example, evidence shows that in economic crises, an increased media coverage may be associated with an increased number of suicides. Thus, the close cooperation between media representatives and experts in the field of mental health and the provision of guidelines during economic crises will have a positive effect on appeasing the psychological disruption of society (31). The broadcasting organization as a mass media can promote social vitality among people and improve the mental health of society by producing and broadcasting joyful and uplifting programs.

The prevalence of drug and alcohol abuse is another important risk factor for mental health promotion. The broadcasting organization can make the society aware of its problems with alcohol and drug abuse by making films and other media content, and in so doing, it can institutionalize a culture of drug and alcohol rejection in society. In the meantime, the role of organizations such as the Ministry of Health and the Parliament must be highlighted. Unfortunately, despite being an Islamic country, Iran is facing a $2.31 \%$ alcohol abuse rate among the youth (32) and a $2.44 \%$ drug abuse rate (33). Drug abuse, alcohol abuse, and domestic violence cause mental problems in parents and are considered strong stressors both for parents and children (34). A tendency to drugs is for adaptation to hard living conditions, temporary relief, and escape from fear or embarrassment. Despite the temporary positive effects of alcohol on mental health, its long-term use can increase stress, depression, memory loss, and suicide. Since drug and alcohol abuse is also rooted in cultural, social, and economic factors (35), proper education to help people adapt to different living conditions is a key issue. Sanctions and the families' difficult subsistence, inflation, inability to make a living, and other unpleasant consequences could increase the drug and alcohol consumption statistics.

\section{Ministry of Cooperatives, Labor, and Social Welfare}

Duties of the Ministry of Cooperatives, Labor, and Social Welfare in the field of employment include policy-making and planning for regulating labor relations, solving the problems of the working class, regulating employer-employee relations using trilateral mechanisms in line with the policy of labor force protection, setting regulations, criteria, safety, and labor standards, determining the minimum wage of workers in the High Council of Labor, and defining employment and planning policies within the framework of major government programs and policies (36). Numerous studies have been conducted on the negative effects of unemployment. Unemployment and job insecurity are among the most important determinants of mental health. The Ministry of Cooperatives, Labor, and Social Welfare plays a key role in supporting job opportunities with healthy and productive working conditions. Job insecurity is a risk factor that can lead to 
poor mental health (22). Unemployment and poor working relations (lack of independence, overwhelming workload, and low rewards) will often lead to stress and mental problems. Based on the statistics from the UK, unemployed people suffer from anxiety and depression 10-14 times more than others (37).

There is a distinction between good employment and bad employment, good work is defined as one that is associated with fair treatment, choice, security, and reward (34). A good job promotes the mental health of people through empowering them to participate in the society, inculcating a sense of independence, and affording housing, food, clothing, and leisure. Studies have demonstrated that the factors decreasing the sense of control, such as job insecurity, low income, and unfavorable workplace conditions, could be more damaging than unemployment (22).

In addition, the Ministry of Welfare can provide more effective support to families that are responsible for taking care of a patient or disabled person or have experienced several adverse events in adulthood (divorce, disability, loss of family members, etc.), because being in such a situation can induce the feeling of isolation and lack of social support and can seriously damage the mental health of such people. Research indicates the impact of parental mental problems on children's mental health and well-being at other stages of childhood (34).

Legislation and political choices that lead to events such as recession can affect health. Recession can intensify poverty and income inequality in societies, which in turn lead to poor mental health (38). As people fall from their socioeconomic status due to unemployment and lack of income, their health becomes at risk (39). Adopting irrational austerity measures for public services has also affected various demographic groups such as children, families, and the youth, leading to long-term and costly psychological and physical damage and challenging the economic growth of society. In this regard, the Ministry of Welfare has policy-making and planning duties to coordinate different sectors of the government with the aim of preventing social harms and determining absolute and relative poverty.

Lack of access to sources in society, such as friendship networks, facilities for children, opportunities for exercising, environmental and social inequalities, stigma and discrimination all affect the mental health of adults. A systematic review conducted in 2009 showed that environmental and socioeconomic status, as well as the place of residence, are important factors in the health and functioning of adults, and the impacts of this deprivation continue until later in life (40). The Ministry of Welfare can play a major role given the tasks of policy-making and planning to protect the society against economic and social adverse events.

Policy-making and planning to provide minimum living standards for the society while prioritizing low-income families and those with physical and mental disabilities within the framework of the comprehensive welfare and social security system are the other duties of this ministry, which could impact the mental health of the society through a lack of basic living conditions (safe water, sanitation, safe nutrition, etc.). The emotional and cognitive effects of social differentiation are profound. A higher degree of inequality increases competition and insecurity in all income and age groups. Inequality in society can lead to feelings of anger, despair, shame, deprivation, and lack of control over people's living conditions and result in stress (22). Thus, the distribution of socioeconomic resources affects health. Social support for all people, in particular the vulnerable groups such as working children, street children, single women, the elderly, non-skilled young people looking for work, families with incurable or disabled patients, and prisoners and their families, is essential for maintaining and improving people's mental health. The role of the Ministry of Cooperatives, Labor, and Social Welfare in supporting prisoners upon release from prison can affect the mental health of this group.

An inappropriate retirement system is another risk factor affecting society's mental health. Given Iran's aging population, the responsibilities of organizations such as the Civil Servants Pension Organization and the Ministry of Cooperatives, Labor, and Social Welfare are more salient. Retirement can be a time of good health; however, compulsory and early retirement, feeling of being compelled to continue working for economic needs, feeling of being inactive in meaningful affairs, or having limited relationships with the family and friends, can increase the likelihood of dementia and depression in individuals (34, 41). The Ministry of Cooperatives, Labor, and Social Welfare has a defined task to conduct economic studies on the financing system and partnership to sustain the financing resources of social and insurance funds as well as integrate and pursue macro-welfare policies to create social and economic justice (36); thus, it can improve retirement conditions, reduce the post-retirement stresses of employees, and bring about mental health promotion.

\section{Ministry of Education}

One of the tasks of the Ministry of Education is the development and spread of physical education (42). Since one of the risk factors affecting mental health promotion is inactivity and lack of exercise, by overcoming some of the barriers to involvement in sports (financial barriers, lack of time, low self-esteem, and lack of athletic facilities), people can become better involved in physical activities. Policymakers such as the Ministry of Sports and Youth, Ministry of Education, Ministry of Roads \& Urban Development, and the Islamic Republic of Iran Broadcasting can play a major role in facilitating the access to all kinds of sports (structured and competitive physical activities, planned and purposeful physical activities for fitness, games and daily physical activities) (43). Physical activity also enhances physical and mental health by promoting a feeling of competence, peace, and social support (44).

The Ministry of Education can coordinate education in the national education system through cooperation with the Ministry of Culture, the Ministry of Health and Medical Education, and other institutions that are in some way involved with education. Given the importance of self-efficacy and life skills for adolescents and the youth, one way to prevent mental and behavioral problems is mental capacity building which, through teaching life skills, can reduce drug abuse, prevent violent behaviors, enhance self-esteem, teach skills for dealing with stress, and promote positive and effective relationships (45).

Meeting educational needs, including equipment, educational facilities, covering all children in need of education, and enhancing the literacy movement are among the tasks of the Ministry of Education (42) which are associated with the risk factor of not receiving education and academic success. The role of the Ministry of Education in mental health promotion is undeniable. Schools are where children spend half of their daily life; thus, they are regarded as a good environment for boosting mental health. Learning plays an important role in a child's social and cognitive development and creates self-esteem and teaches children social interactions (46). Education means lifelong learning (47). At any age, it reduces the risk of disorders such as depression, particularly in women 
(48). Learning has also been effective in increasing income and job creation, which also affect life satisfaction and mental health promotion (49). A low level of education is a risk factor for the occurrence of psychological problems (48).

According to reports, children who do not have a positive experience with education or are deprived of education suffer from higher levels of anxiety (50). A good school understands the relationship between mental health and educational outcomes and provides effective systems for monitoring and solving the problems of children and adolescents. For youth at risk of behavioral or emotional risks, schools should provide the conditions that boost their resilience through behavioral support, school counseling, and parent-centered interventions. Schools must challenge the stigma and discrimination on mental health and ensure that the school staff and students have sufficient knowledge of mental health and know when and how to ask for help (23).

It is worth noting that learning improves health by affecting four types of capital, including economic capital (employment opportunity), human capital (awareness and knowledge), social capital (levels of civic interaction and social cohesion), and identity capital (self-confidence and self-respect) (22).

Poor planning for the early years of life is another determinant of mental health. Separation from or loss of parents (due to divorce, hospitalization, death, etc.), changes in life (such as changing the school or place of residence), and traumatic events (violence, abuse, accidents, and natural disasters (51) are the major traumatic factors of this period. In order to maintain and improve the health of people in dealing with such events, planning must be performed by relevant organizations. Meanwhile, with respect to its duty in performing necessary actions to provide, maintain, and promote the physical, mental, and social health of the students in collaboration with the Ministry of Health and Medical Education, the Ministry of Education can play a major role in improving the conditions for children, adolescents, and youth.

Numerous studies have examined the inter-sectoral actions of health and determined the role of organizations in this domain. For example, Fisher et al. (2016) noted that the major institutions involved in inter-sectoral actions about the social determinants affecting health and justice are the department of education, social services, sports organizations, the police, the judiciary system, urban planning and, to a lesser extent, the department of environment (52). Skeen et al. (2010) explained the role of institutions, such as the department of housing, judiciary, correctional services, the police, social welfare, the education sector, and the labor sector as effective institutions on mental health promotion in Africa (53). Damari (2016), in an article on the share and role of five factors affecting mental health risk factors, reported the ministry of health, ministry of interior, ministry of education, ministry of welfare and social security, and broadcasting organization as five important entities (54), a result which is in line with the institutions identified in the present study. The small differences between the two studies may be due to the changes in the economic and political conditions of the society since the process of stakeholder identification is dynamic and the related stakeholders could slightly vary across societies. In the present study, the Ministry of Health is ranked the eighth in terms of impact on mental health risk factors, and this indicates the need for greater attention in the inter-sectoral cooperation regarding health, especially mental health.

In addition to studies carried out on the role of organizations or stakeholders in different aspects of health, in the Ottawa Charter that is one of the earliest charters about inter-sectoral health actions, the importance of institutions such as the department of education, department of labor, and the parliament has also been mentioned. In this charter, the importance of providing supportive health environments (peer education, problem-solving skills, negotiation and social skills in schools, lower unemployment pressure, improved housing conditions, and reduced stigma), building individual skills (improved resilience and access to education for adults, dealing with stress), and formulating healthy public policies (healthy workplace policies, good working conditions, and workplace well-being promotion) is noted (55).

\section{Conclusions}

It can be argued that mental health policies must give consultation to the other departments on mental health promotion. Any uncertain political orientation, lack of coordination, defragmentation, and inefficiency weakens health interventions. In the case of failure and limiting the political scope of health promotion to the health domain, the number of stakeholders with active participation and commitment to health promotion will become limited (56). Key actions suggested to promote, maintain, and restore mental health are as follows: providing better information, awareness, and education about health and mental diseases, and increasing social and legal financial protection for families and communities affected by mental disorders (57).

In this study, the organizations effective on mental health in the current Iranian society were identified. Although the Ministry of Health and Medical Education is responsible for the health system in Iran as the main administrator of mental and physical health, the impacts of other institutions on mental and physical health cannot be ignored. As found in this study, the impacts of institutions such as the Islamic Consultative Assembly (as the legislator), the Ministry of Interior and its subsidiary entities such as municipalities and governors (as the administrators of homeland security and support for safe and appropriate urban and local facilities), the Islamic Republic of Iran Broadcasting (as the national media), the Ministry of Cooperatives, Labor, and Social Welfare (which is in charge of employment, job security, and welfare, especially for vulnerable groups), and the Ministry of Education (as the educational institution of the country) are significant on mental health promotion. The findings of this study revealed the multilateral impact of different organizations through social determinants on mental health promotion.

\section{Abbreviations}

SAW

Simple additive weighting

AHP

Analytic hierarchy process

\section{Declarations}


Ethics approval and Consent to participate:: Ethical approval for this study was obtained by ethical committee of Kerman University of Medical Sciences.The Ethic approval Cod is IR.KMU.REC.1398.287. Prior to filling out the relevant checklist, verbal satisfaction was obtained for respondents (first group), and for cases that the checklists were emailed, individuals were asked to respond if they wished. All participants were explained that participation in the research is completely voluntarily, according to the ethical rules of the research.Consent for publication: Not applicable.

Availability of Data and Materials: The datasets supporting the conclusions of this article are included within the article (and its additional files).

Competing Interest: No declared

Funding: Not applicable.

Authors' contributions: All the authors contributed equally, and all of them read and approved the final manuscript.

Acknowledgments: Not applicable.

\section{References}

1. Hajebi A, Damari B, Moghaddam AV, Nasehi A, Nikfarjam A, Bolhari J. What to do to promote mental health of the society. Iranian journal of public health. 2013;42(Supple1):105.

2. The distribution of the common mental disorders

Fryers T, Melzer D, Jenkins R, Brugha T. The distribution of the common mental disorders.

3. social inequalities in Europe. Clinical Practice Epidemiology in Mental Health. 2005;1(1):14.

4. Laaksonen E, Martikainen P, Lahelma E, Lallukka T, Rahkonen O, Head J, et al. Socioeconomic 505 circumstances and common mental disorders among Finnish and British public sector employees: evidence from the Helsinki Health Study and the Whitehall II Study. Int J Epidemiol. 2007;36(4):776-86.

5. De Vogli R, Gimeno D. Changes in income inequality and suicide rates after "shock therapy\&\#8221.

6. evidence from Eastern Europe. Journal of Epidemiology Community Health. 2009;63(11):956-6.

7. De Leeuw E, Simos J. Healthy cities: the theory, policy, and practice of value-based urban.

8. Springer planning. Springer; 2017.

9. Finegood DT. The complex systems science of obesity. The Oxford handbook of the social.

10. science of obesity2011.

11. Moodie R, Jenkins R. I'm from the government and you want me to invest in mental health.

12. promotion. Well why should I? Promotion \& education. 2005; 12(2_suppl):37-41.

13. A Framework for Supporting Action in Population

Mantoura P, Roberge M-C, Fournier L. A Framework for Supporting Action in Population.

14. Mental Health. National Collaborating Centre for Healthy Public Policy; 2017.

15. World Health Organization. The Helsinki Statement on Health in All Polic. 8th Global.

16. Conference on Health Promot; Helsinki (Finland): World Health Organization; 2013.

17. World Health Organization. World Conference on Social Determinants of Heal. All for Equity Meeting Report Rio+; Río de Janeiro: World Health Organization; 2011.

18. Tools for Stakeholder

Multi-stakeholder management

Zimmermann A, Maennling C.Multi-stakeholder management: Tools for Stakeholder.

19. Analysis. 10 building blocks for designing participatory systems of cooperation. Deutsche.

20. Gesellschaft für Technische Zusammenarbeit (GTZ). GmbH Postfach. 2007;5180:65726.

21. Schmeer K. Stakeholder analysis guidelines. Policy toolkit for strengthening health sector.

22. reform. 1999:1-33.

23. World Health Organization. Prevention and Promotion in Mental Health. 2002.

24. World Health Organization. Prevention of mental disorders: effective interventions and policy options: summary report. 2004.

25. Commission on Social Determinants of Health. Geneva WHO. Closing the gap in a generation: health equity through action on the social determinants of health. 2008.

26. World Health Organization. Risks to mental health: an overview of vulnerabilities and risk factors. 2012.

27. Putra DWT, Punggara AA. Comparison Analysis of Simple Additive Weighting (SAW) and Weigthed Product (WP) In Decision Support Systems. MATEC Web of Conferences; 2018: EDP Sciences.

28. Government and Parliament Interaction in the Islamic

Azar A, Rahpeik S, Talaiee Nik R. Government and Parliament Interaction in the Islamic.

29. Republic of Iran. a Strategic Model. Interdisciplinary Studies on Strategic Knowledge.

Page $8 / 11$ 
30. 2017.; 1(2):45-69.

31. Khalili M. The Comparative Constitutional Law System and Regional Studies Discipline.

32. 2

79

98

Central Eurasia S. 2010; 2(5): 79-98.

33. Iraj M. A Pathological Study on Legal Status of Supreme Councils in the Islamic Republic of Iran. Bulletin de la Société Royale des Sciences de Liège. 2017.

34. economic, human rights and Jenkins R, Baingana F, Ahmad R, McDaid D, Atun R. Social. economic, human rights and.

35. political challenges to global mental health. Mental Health in Family Medicine. 2011;8(2):87.

36. Cooke A, Friedli L, Coggins T, Edmonds N, Michaelson J, O'hara K, et al. Mental Wellbeing Impact Assessment: a toolkit for wellbeing. London: National MWIA Collaborative (England); 2011.

37. Centre for Mental Health DoH

NHS Confederation Mental Health Network RMI

Centre for Mental Health DoH. Mind. NHS Confederation Mental Health Network RMI.

38. Point T. No Health without Mental Health: Implementation Framework. 2012.

39. Debt, income and

Jenkins R, Bhugra D, Bebbington P, Brugha T, Farrell M, Coid J, et al. Debt, income and.

40. mental disorder in the general population. Psychological medicine. 2008;38(10):1485-93.

41. Harker L. Chance of a lifetime: the impact of bad housing on children's lives: Shelter UK.

42. 2006.

43. 26. Sharifzadeh Ha-S, Mirmohammad Tabar SA, Adlipour S. A Study of Factors Affecting Social Happiness in Iran: A Meta-analysis of Conducted Research. Scientific Journal Management System. 2018; 10(40):159 - 80.

44. 27. Vice President of Management Development and Human Capital. Ministry of Interior's set of goals, tasks and organizational positions. Deputy of Administrative Renovation Organizational Structure Affairs; 2014. http://tahavol.ostan-

chb.ir/afiles/up/tahavol/36/other/\%D8\%A2\%D9\%85\%D9\%88\%D8\%B2\%D8\%B4/\%D8\%B4\%D8\%B1\%D8\%AD\%20\%D9\%88\%D8\%B8\%D8\%A7\%D9\%8A\%D9\%

45. 28. Goldie I. Public mental health today: a handbook: Pavilion Publishing; 2010.

46. 29. Thomson H, Petticrew M, Morrison D. Health effects of housing improvement: systematic

47. review of intervention studies.BMJ (Clinical research ed). 2001;323(7306):187 - 90.

48. 30. Murthy RS, Lakshminarayana R. Mental health consequences of war: a brief review of research findings. World psychiatry. $2006 ; 5(1): 25$.

49. 31. Wahlbeck K, McDaid D. Actions to alleviate the mental health impact of the economic crisis. World psychiatry. 2012; $11(3): 139-45$.

50. 32. Nikfarjam A, Hajimaghsoudi S, Rastegari A, Haghdoost AA, Nasehi AA, Memaryan N,et al.

51. The frequency of alcohol use in Iranian urban population: the results of a national network scale

52. up survey. International journal of health policy and management. 2017; 6(2):97.

53. 33. Mohebbi E, Haghdoost AA, Noroozi A, Vardanjani HM, Hajebi A, Nikbakht R, et al.

54. Awareness and attitude towards opioid and stimulant use and lifetime prevalence of the drugs: $A$

55 . study in 5 large cities of Iran. International journal of health policy and management.

56. 2019.; 8(4):222.

57. 34. Regan M, Elliott I, Goldie I. Better Mental Health for All: A Public Health Approach to Mental Health Improvement. Faculty of Public Health, and Mental Health Foundation London. 2016.

58. 35. Mohammadpoor Lima H, Mohseni Tabrizi Ar. A Sociological Explanation of Effective Factors on Tendency Toward Risky Behavior in the Rural Areas of Guilan province (Case Study: Drug Abuse and Addiction in the Eshkevar Rural Areas, RahimAbad District of Rudsar). Journal of Social Problems of Iran. 2018; 8(2):191-207.

59. 36. Available from: https://www.mcls.gov.ir/fa/aboutus/tasks.

60. 37. Stansfeld S, Candy B. Psychosocial work environment and mental health-a meta-analytic

61. review. Scandinavian journal of work, environment \& health. 2006:443 - 62.

62. 38. Pickett KE, Wilkinson RG. Inequality: an under acknowledged source of mental illness and

63. distress. The British Journal of Psychiatry. 2010; 197(6):426-8.

64. 39. Wilkinson RG, Marmot M. Social determinants of health: the solid facts: World Health

65. Organization; 2003.

66. 40. Yen IH, Michael YL, Perdue L. Neighborhood environment in studies of health of older adults: a systematic review. American journal of preventive medicine. 2009;37(5):455 - 63.

67. 41. Morgan A, Swann C. Social capital for health: issues of definition, measurement and links to

Page 9/11 
68. health: Health Development Agency; 2004.

69. 42. Available from: https://rc.majlis.ir/fa/law/show/91482.

70. 43. Edmunds Sarah, Biggs Hannah, Isabella. G. The impact of physical activity on wellbeing.

71. 2013

72. 44. Caldwell LL. Leisure and health: Why is leisure therapeutic? British Journal of Guidance \&

73. Counselling. 2005; 33(1):7-26.

74. 45. Naeim M, Rahimi HR, Soltani F, Farazandeh F, Maghsoodloo Nejad F, Sharafi MR,et al. The role of life skills and self-efficacy in mental health among male students in High school. International Journal of Medical Research \& Health Sciences. 2016;5(7):118 - 26.

75. 46. Kirkwood TB, Bond J, May C, McKeith I, Teh MM.Foresight Mental Capital and Wellbeing

76. Project: Mental Capital Through Life: Future Challenges. Wellbeing: A Complete Reference

77. Guide. 2014:1-90.

78. 47. Anderson LM, Shinn C, Fullilove MT, Scrimshaw SC, Fielding JE, Normand J, et al.The

79. effectiveness of early childhood development programs: A systematic review. American journal of preventive medicine. 2003; 24(3):32-46.

80. 48. Feinstein L, Hammond C. The contribution of adult learning to health and social capital.

81. Oxford Review of Education. 2004; 30(2):199-221.

82. 49. Searle B. Well-being: In search of a good life?: Policy Press; 2008.

83. 50. Milburn M. Prince's Trust Youth Index 2017 Macquarie. Prince's Trust. 2017.

84. 51. Department of Ecucation and Skill (DfEE). Promoting children's mental health within early

85. years and school settings. DfEE London; 2001.

86. 52. Fisher M, Baum FE, MacDougall C, Newman L, McDermott D, Phillips C. Intersectoral action on SDH and equity in Australian health policy. Health promotion international.2016; 32(6):953 - 63.

87. 53. Skeen S, Kleintjes S, Lund C, Petersen I, Bhana A, Flisher AJ, et al. 'Mental health is

88. everybody's business': roles for an intersectoral approach in South Africa. International Review of Psychiatry. $2010 ; 22(6)$ :611 - 23.

89. 54. Damari B. Role and share of iranian governmental organizations in public's health.

90. 2015.; 14(5):511-521.

91. 55. Bonnie P. Discussion paper on mental health promotion. 2006.

92. 56. Herrman H, Saxena S, Moodie R. Promoting mental health: 624 concepts, emerging evidence, practice: a report of the World Health Organization,Department of Mental Health and Substance Abuse in collaboration with the Victorian Health Promotion Foundation and the University of Melbourne: World Health Organization;2005.

93. 57. World Health Organization. Investing in mental health: evidence for action. 2013.

\section{Tables}

Due to technical limitations, table 1, 2 \& 3 is only available as a download in the Supplemental Files section.

\section{Figures}

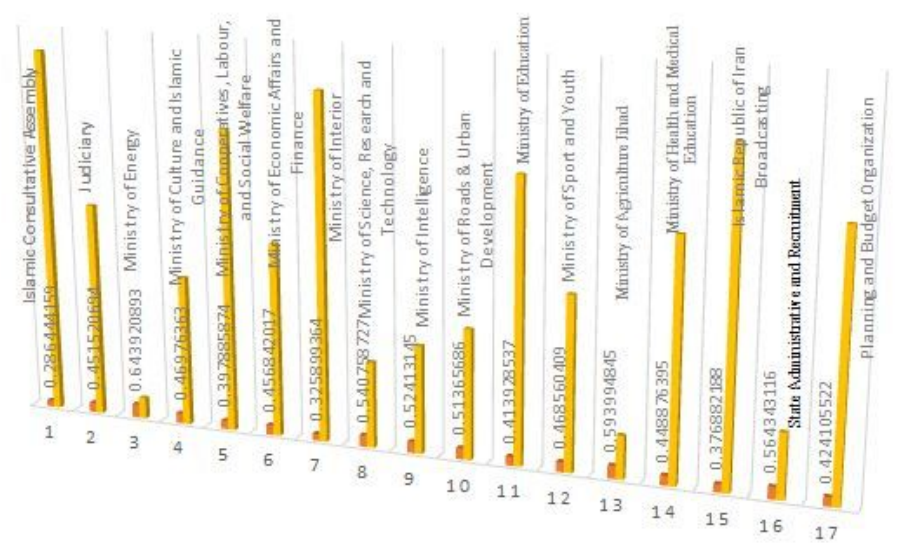

Figure 1

Ranks of institutions on mental health promotion risk factors 


\section{Supplementary Files}

This is a list of supplementary files associated with this preprint. Click to download.

- Questionnaire.docx

- CopyofexcelmethodSAW.xlsx

- tablesn.docx 